\title{
Enduring Nature
}

\author{
Glenn Deliège
}

\section{Introduction}

In his contribution to this volume, Paul Knights argues that some of the most notorious antirestoration arguments, those worked out by Eric Katz and Robert Elliot, are in need of a revision if they are to be relevant to the practice of nature restorations in the Old World. ${ }^{1}$ Indeed, Old World nature is very different from New World nature, or at least, it is believed to be different. While in the New World one can still find "wilderness", in the sense of land untouched or relatively untouched by human interference, no such land exists anymore in Europe. At least, that was the story up until the relatively recent past. In the New World now too one is realizing that many landscapes that are deemed "wilderness" are in fact landscapes thoroughly worked over by First Nation peoples. ${ }^{2}$

Although early European conservationist ${ }^{3}$ movements were often influenced by their American counterparts, and as such venerated the ideal of an untouched nature, the realization that much of the cherished landscape would disappear if certain forms of human exploitation of the landscape stopped quickly sunk in. ${ }^{4}$ The European landscape is and was "humanly mediated": a landscape that got its appearance through a delicate interplay between natural processes and human manipulation of those processes. ${ }^{5}$ In traditional, Old Agricultural European landscapes, culture and nature are often so melded together that it is hard to distinguish between the two. What is clear however, is that if certain traditional land uses are changed, the landscape changes with them, often completely changing its appearance and character. Open heaths for instance slowly turn into closed woodlands once grazing, mowing, 
sod cutting and burning are stopped. And with the heath, all species dependant on it disappear too. ${ }^{6}$

In Europe, conservation has therefore always been about trying to maintain old agricultural landscapes in their original, pre-industrialized state. This can be achieved by encouraging locals to keep on managing the land in a traditional way. Increasingly, however, traditional management practices have to be carried out by conservation organizations in special reserves, because the traditional practices have become so unprofitable and unproductive that even a system of subsidies no longer provides an adequate incentive to keep managing the old agricultural landscapes in traditional ways. As Knights correctly points out, this often results in conservation agencies no longer using the traditional management practices, but using practices that "mimic" the traditional ones, practices that have often been tweaked to ensure maximum biodiversity conservation. ${ }^{7}$ This results in landscapes that are often largely similar to, but not exactly the same as the traditional agricultural landscapes they replace.

Given this different ecological context, it is hardly surprising that there are different sensibilities regarding nature conservation practices and the value of nature between the Old and the New World. What stands out the most of course, is the insistence of many North American environmental philosophers on the importance of wilderness, land untouched by human hand. Meddling with nature, even if done in a careful way, is often frowned upon in New World environmental philosophy. The work of Robert Elliot and Eric Katz on nature restorations can be seen as exemplary of this tendency: according to them, restored nature cannot be something else than faked or artificial nature. ${ }^{8}$ Indeed, nature restoration can easily be dismissed as a contradiction in terms once one starts off from the premise that real nature is that which is "untouched by human hands". Such arguments against nature restorations are much harder to make in Europe, as there is no nature left that is untouched by human hands. 
That does not mean however that anything goes as far as nature restorations go in Europe. Knights for instance shows how Elliot's anti-restoration stance can be reinterpreted to evaluate European restoration practices, and that there is a good case to be made that we are under the obligation to try and honor traditional landscapes and their management practices while restoring nature on the basis of their heritage value and the respect we owe to our predecessors. $^{9}$

I will not attempt to develop my own account of why we might be under the obligation to respect traditional agricultural landscapes and the practices that gave rise to them when restoring Old World nature. What interests me here, is how nature still plays a role in the justification and evaluation of restoration practices, especially in an Old World context. Indeed, despite my previous remarks on the different ecological context between the Old and the New World, and the role humans play in that ecology, the idea of nature as something which is pre-given to human action and which we should respect, still plays a crucial role in the evaluation of European restoration practices. What should we make of the appeal to "nature" as an evaluative criterion in the context of the restoration of landscapes that have been thoroughly humanized? I will show that whenever "nature" is invoked as a criterion in European restoration practices, it does not refer to an ontological entity "nature". Rather, such appeals evince of an implicit understanding of the need to reject the instrumentalization of whatever one aims to restore.

In "Environment as Cultural Heritage" Jana Thompson correctly remarks that "many people derive a special value from being in the presence of objects that were actually made or used by people of the past, environments that they actually lived in, scenes they celebrated."10 Sadly, though, she concludes that why this might be so "can be best explained by psychologists". ${ }^{11}$ I believe that philosophers can also have a great deal to say about why this is the case. Certain objects seem to hold a surplus of meaning, in the sense that they point to 
something beyond themselves while at the same time fixing the attention upon themselves as unique and irreplaceable objects. In such instances, we can speak of objects having a "strongly embodied meaning": the meaning, or value, such objects have cannot be expressed or instantiated other than through their particular material manifestations, yet at the same time the meaning they have cannot be reduced to their particular material manifestation either. It is my contention that natural areas posses such strongly embodied meanings, and it is precisely because natural areas or objects posses such meaning, that we reject their instrumentalization.

I will try to prove my case in three steps. First, I will use a recent article by Joachim Mergeay and Luc De Meester to show how "nature" still plays a paradoxical role in European restoration efforts. Next, I'll look at the work of Eric Katz to show how the rejection of the instrumentalization of nature is inherent in the desire to restore nature itself. I will then go on to show how this rejection is tied up with the strongly embodied meaning of natural areas and natural objects, to end with a few remarks on the danger and necessity of permanence in restoration and preservation.

\section{Mowing Meadows}

Restoring nature can be a frustrating affair. Restorationists often have to go through great tribulations, sometimes without getting the desired results from their efforts. Take for instance the restoration of old meadows. An "old meadow" is a technical term for a meadow that has not yet been farmed in a modern, industrial, intensive way. They are typical representatives of the European old agricultural landscape. Old meadow soils usually have a low nitrate content, which results in the presence of an abundant and specific flora. Because present day industrial farming is all about increasing productivity, industrially farmed meadows show a high nitrate soil content through intensive fertilization. Such modern meadows only support a handful very competitive and relatively banal species of plants. Old meadowland is therefore highly 
prized by conservationists. Over the last half century, a lot of it has disappeared, usually through the intensification of farming methods. In some cases, when the intensification of production did not prove cost-effective, old meadows were simply abandoned or planted with poplars. If regular mowing is stopped, all meadows will slowly start to turn into forests, at least in the Western European climate. First, the uncut grass will smother other small and more delicate herbs. Once the grass starts to die back, it will compost and increase the nutrient levels in the soil, leading to the invasion of bigger, more robust and competitive herbs. In between those bigger herbs, the first shrubs and later trees will be able to get a foothold, and once they have matured, their canopy will shade out the remaining typical meadow herbs and grasses. $^{12}$

Because of the intensification of farming and the lack of traditional management on the remaining old meadows, many old meadow species, among which a number of highly valued orchids and fungi, have become very rare, especially in those areas of Europe where agriculture has been strongly intensified, as it is throughout most of Western Europe. Once an old meadow has been intensively farmed, it is usually irrevocably lost, but if it has only been overgrown by trees and shrubs or planted with poplars, it can usually be restored to its former state. Many conservation organizations, when they get a hold of some piece of reforested old meadow, will therefore decide to restore it to its previous condition. Restoring meadowland from forest is however a strenuous effort: first, the trees and shrubs need to be removed. For this task one cannot use heavy machinery, because this would compact the soil too much. All trees need to be manually chainsawed and the logs need to be hauled out by hand or horse. Once trees and shrubs are removed, the area will have to be mown regularly, as the first plants that reappear after clearcutting will be weedy, competitive herbs and grasses that can profit from the nutrients that have built up in the soil during the process of reforestation, not the more delicate, less competitive herbs and grasses of the old meadowland. Again, no tractors 
can usually be involved in this process because of the risk of soil compaction, so mowing has to occur by string trimmer or even scythe, and the hay needs to transported out by hand on special stretchers. The first couple of years, this mowing processes needs to be intensive to fight back resilient herbs and shrubs such as brambles and bracken, and even once they have gone, meadows need to be mown at least once a year in order not to let it turn into a forest again. A break in mowing can mean that the work of many years is lost. All of this needs to be done respecting the seasons and the life-cycles of the species affected by the process.

Restorationists do all of this work without any guarantee that their restoration process will be successful. Usually, some typical meadow plants will return after a restoration process, but in a lot of cases the most highly prized, really rare species do not return. Many typical meadow orchids, for instance, are picky about growing conditions, and despite the best of care, they often do not return to restored areas. In some cases, the non-returning species simply cannot return because they have no viable seeds in the remaining seedbank, or because the nearest existing populations are too far removed to be able to disperse naturally to the restored areas. In such cases, many restorationists, at least in Europe, do nothing except for maintaining the restored old meadows, in the hope that one day, maybe, luck will come their way and the lost species will return. What else could they do?

\section{Being rational about reintroductions}

According to Joachim Mergeay and Luc De Meester, restorationists can do much more than simply keep up traditional management practices in the hope of a miraculous return of lost species. ${ }^{13}$ They claim that waiting for the spontaneous colonization of target species is in many instances a form of eco-masochism. ${ }^{14}$ In order to save the rarest and most endangered species, we need to work on habitat restoration, increase the connectivity between habitats and increase population sizes. But achieving those goals is a very long-term process, and 
many of the rarest species no longer have long-term prospects. Moreover, according to Mergeay and De Meester, there are "priority effects" to take into account: newly restored areas can get colonized by opportunistic species already present in the vicinity, making the restored areas unsuitable for the resettlement of target species for long stretches of time, sometimes even permanently. Given the fact that the most endangered species only exist in small, isolated populations, they are least likely to be able to quickly resettle newly restored areas, and are thus most likely to fall victim to priority effects.

Given these circumstances, one should, according to Mergeay and De Meester, consider actively reintroducing missing target species to restoration areas, so they can gain a foothold before the opportunists arrive. Mergeay and De Meester note however that there is still a taboo on actively reintroducing target species as part of a restoration process. That taboo is often justified on the basis of the fact that nature conservation should primarily be directed at letting spontaneous natural processes run as freely as possible. But, Mergeay and De Meester note, that justification is inconsistent. European nature is a humanly mediated nature to start with, and restoring it will always entail further human mediation. How can one judge that actively reintroducing species is "too unnatural", but for instance mowing a meadow is not? It seems that the difference made between active reintroduction and mowing a meadow is purely arbitrary, a question of sentiment. Nature conservation is not served by sentimentality, indeed, sentimentality about spontaneous processes can be dangerous when it leads to the disappearance of rare species. Therefore, they propose to tackle the taboo on reintroductions on a rational basis.

\section{Biodiversity as Pandora's box}

According to Meregay and De Meester, the taboo on reintroductions is based on a confusion between means and ends. The end of conservation should be the conservation of biodiversity. 
To achieve that end conservationists can use any number of means, one of which is letting spontaneous natural processes occur. If however the target species of a restoration project does not spontaneously recolonize a restored area, one should consider actively reintroducing it. Holding on to the primacy of spontaneous processes is in such a case confusing means and ends: the end is the conservation of biodiversity, the means are spontaneous processes. Means should be judged solely on the efficiency with which they achieve the desired ends, and if they prove to be inefficient, they should be replaced by more efficient ones.

Mergeay and De Meester's argument is well taken: if the final goal of all conservation is in essence the conservation of biodiversity, then it is not clear why we should be so concerned with allowing for spontaneous processes. Indeed, the problem is that once one accepts that biodiversity conservation is the absolute goal of nature conservation, Pandora's Box is opened. Biodiversity is, at least according to one standard definition, nothing more than the variety of genes, species and ecosystems. "Spontaneous natural processes" as such are no part of biodiversity: they might give rise to biodiversity, but not necessarily so. If one wants to conserve biodiversity, one therefore does not necessarily have to bother with spontaneous natural processes. Genes can be stored in gene banks, and increasingly, humans can create diverse genetic lines themselves. Species can be just as well preserved in botanical gardens and zoo's as they can be in wildernesses. Ecosystems that support diverse gene pools and species can be ones that are influenced, manipulated or even created by humans. Moreover, the goal of biodiversity conservation will sometimes force humans to intervene and manage when species, gene pools or ecosystems are under threat, such as when we are forced to reintroduce species to avoid "priority effects" in restored areas. ${ }^{15}$ As a result, one could even envisage a totally managed world in which there is no threat of biodiversity loss but where there is no longer any room for spontaneous natural processes. 
Such a totally managed world is not however what conservationists are after. ${ }^{16}$ Conservationists are also concerned with spontaneous natural processes. Even Mergeay and De Meester have to concede that. In the conclusion of their paper, they mention that although they believe that there is a good case to be made against the taboo on reintroductions, one should also try to avoid too much "gardening" in nature reserves. ${ }^{17}$ Yes, it is all about biodiversity, but only biodiversity begotten as naturally as possible. Spontaneous natural processes can never be a mere means: it is the preferred means, and sometimes they are an end in itself. ${ }^{18}$ The clear distinction Mergeay and De Meester wanted to draw between means and ends, appears not to be so clear after all, and in the end Mergeay and De Meester are faced with the same kind of inconsistency they reproach the adversaries of introductions: they arbitrarily introduce the concept of nature in order to ban certain conservation practices. Arbitrarily, because on the one hand they have no problem with interfering with nature when it comes to traditional management and reintroductions and on the other hand the importance attached to nature as an evaluative criterion to ban certain conservation practices cannot be deduced from the overall goal of conservation: the conservation of biodiversity. If conservation is only about biodiversity conservation, there is no aprori reason why we should care about spontaneous natural processes.

So, there seems to be something unassailable about the importance attached to spontaneous natural processes, even in an attempt to downplay that importance. There is something about human mediation and manipulation of nature that bugs us. But why is that? What could it mean to use "naturalness" as an evaluative norm in a context of a thoroughly humanly mediated nature? Why should we value "naturalness" in the first place, or more saliently, why should it be a concern in any conservation effort? Can invoking "naturalness" as an evaluative criterion in Old World conservation be anything else than arbitrary? Maybe it is best to start looking for answers in New World environmental philosophy, as it is there that 
spontaneous nature, or a nature untouched by human hand, takes center stage. And were better to look than in the work of Eric Katz, where the spontaneity of nature plays a key role.

\section{Katz and the domination over nature}

Eric Katz is probably best known for his sustained attack against the acceptance of restored nature as real nature. According to Katz, nature restorations are all about remolding nature to better suit human satisfactions and interests. ${ }^{19}$ When we engage in nature restoration or management, we reconstruct: "the natural world in our own image, to suit our purposes", (115) whereby we: "manipulate natural processes to create the most pleasant human experience possible" (114). In doing so, we are making nature into an artifact, and artifacts are: "as human instruments [...] always a means to the furtherance of some human end" (129). That "human end" which restorations serve is, according to Katz: "the creation of environments that are pleasing to the human population" (101), and to create environments that: "provide us the pleasant illusory appearance of the natural environment" (105). In others words, a restored natural area is not nature at all, it is an artifact that gratifies our need for a pleasurable nature experience. In nature restorations, nature is instrumentalized to serve human purposes.

Why is such an instrumentalization problematic? Katz gives two distinct answers. First: "what makes the value of the artificially restored natural environment questionable is its ostensible claim to be original" (114). Here, Katz stays close to that other great adversary of nature restoration, Robert Elliot: restored nature is faked nature, it passes artifacts off as

nature, and that is deceitful. ${ }^{20}$ Second, Katz believes that in instrumentalizing nature we deny its autonomy. Nature is not created to fulfill any human purpose, indeed, it is "intrinsically functionless", meaning that "[it is] not created for any particular purpose; [it has] no set manner of use". ${ }^{21}$ Furthermore: "nature is not merely the object of technological practice and 
alteration; it is also a subject, with its own process and history independent of human intervention and activity" (115-116). Nature thus has autonomy: it has its own trajectory of development quite distinct from human purposefulness. Therefore, following a broadly Kantian line, nature should be seen as an autonomous entity that should never be treated as a mere end to further certain human goals. Denying nature its autonomy through instrumentalizing it in order to attain human goals is therefore a form of domination. Both humans and nature are partners "in the continuous struggle for the preservation of autonomy, freedom and integrity" (117), and because we are shared partners on this project, humans have an obligation to preserve and protect the natural world.

\section{The externality of the object of desire}

According to Katz, the problem with nature restorations is that it makes nature solely answerable to our desires, whereby nature is relegated to an artificial means to satisfy those desires. There is a good deal to say about that conclusion: nature restorations can result in the instrumentalization of nature, and this danger becomes acute when it is believed that the goal of all restoration efforts should be defined in the general terms of biodiversity conservation. Later, I will return to this point. However, I want to argue contra Katz that the desire to restore nature itself already contains a rejection of the instrumentalization of nature. This rejection is not based on the specific ontological status of the object of that desire (the autonomy of nature), but with the structure of the desire itself. ${ }^{22}$

In Katz's view, all nature restorations are primarily manipulative in character. His theory seems to imply that the restorationist first forms himself an internal image of what a pleasurable nature experience is like, and then sets out to manipulate nature in such a way that it will generate precisely those experiences. But it seems to me that experiences of nature are not what restorationists are after, they are after the genuine article: nature. This is of course 
precisely the point Robert Elliot raised in his famous article and later book Faking Nature. Elliot argues that for someone who is interested in nature it is not enough that a putatively natural area is experienced as being natural. Nature is of value for a nature enthusiast not because of the states of mind that are engendered by experiencing nature, but because of what it is: nature. We do not just want any experience: we want to "world to be a certain way" so that we can have "veridical" experiences. ${ }^{23}$

Elliot intuitively proves this point by a set of three well-known thought experiments about a wilderness enthusiast called John, of which I will only discuss the first. In it, John falls into the hands of a "utilitarian minded supertechnologist". By means of an experience machine he is given the wilderness experience of a lifetime. After John is told that it was all a "cruel hoax", he however feels cheated. This thought experiment shows that John is not interested in experiences of nature per se, but that through his experiences he wants to be in the presence of, wants to get into contact with, the reality which he most values: nature. He shows that he is prepared to sacrifice the knowledge and memory of his sensational wilderness experience while hooked up to the experience machine because it turned out that it did not occur in the presence of real wilderness, although the experiences themselves were at that time indistinguishable from experiences he might have had when he would have been in the presence of real wilderness. If one thus values nature, and seeks to be in its presence, this is not only because of the experiences one expects to get from it, one wants to get through to its reality, one wants reality to be a certain way, and one wants to be in the presence of that reality. As a consequence, we cannot see that reality as a mere instrument to give us those experiences. That which we value is precisely transcendent vis-à-vis our experiences: we go searching for it even beyond whatever experiences we expect to get from it.

With Katz I agree there is a problem with the instrumentalization of nature, but against Katz I do not believe this problem to be the result of the specific ontological properties nature 
has. All acts of conservation are a response to a prior appeal from nature: nature makes an appeal on us, appears as something of great meaning, installing in us a desire to be in its presence. It belongs to the structure of the desire generated by the appeal from nature itself that we do not want to instrumentalize the object of that desire. We want to be in the presence of the object itself and treating it as a mere means would imply that we would only desire some experiences or products by means of that object. We would then be able to discard the object of our desire if we were to find means that achieve this goal more efficiently. In such a case the object itself in its concrete thereness has no value of its own, we will "look through it" to achieve some other goal, while in fact it should be the source and focus of our desire. The desire to be in the presence of nature, to want to conserve the presence of nature, thus starts with a moment of passivity in front of nature in which nature makes an appeal on us as a source of meaning or value which needs to be respected and honored in its own right. Nature itself appears as the transcendent source of our desires, and conservation is all about respecting nature as a source of those desires. There is no fundamental difference here between preservation and restoration: both start from this prior moment of passivity in front of nature. It is only when one is first struck by the appeal that comes from nature itself that one can desire to restore or preserve it. For both nature restoration and nature preservation, respecting nature then entails respecting its transcendence. In both practices nature must remain fundamentally external to our desires, guard a certain independence vis-à-vis our desires as their transcendent source, in order to be able to satisfy the kind of desire that is generated by it.

In conservation, nature should thus not be seen as an instrument to satisfy certain desires we can specify independently from the concrete way in which nature presents itself to us. That is however precisely what Mergeay and De Meester propose to do. Mergeay and De Meester believe, together with a growing group of conservationists, that conservation should 
all be about biodiversity. Nature conservation is then no longer about respecting nature as the transcendent source of our desires, but about (re)constructing nature in such a way that it complies with our desires. Nature can and should be so reconstructed that it satisfies our desire to maintain levels of biodiversity. Consequently, Mergeay and De Meester fall into the restoration trap described by Katz: by specifying a goal for conservation which is independent from the concrete way in which nature manifests itself they open the door for the reconstructing nature in such a way that it complies with the goal we have in mind for it, thereby relegating nature to the status of a mere means to satisfy our desires. What starts as an attempt to conserve nature thus ends up with negating the importance of nature altogether.

The problem is however not that in doing so we make nature into an artifact and that non-artificial nature (or "intrinsically functionless nature" in the words of Katz) represents a special type of value. The problem is that the appeal nature makes on us is to be respected in its own right, and this appeal cannot be answered in merely manipulative terms. The task of all conservation, whether it is restoration or preservation, is therefore not primarily to manipulate nature, but rather to interpret nature in such a way that we can attain a fitting attitude towards the appeal it makes on us. Nature restoration efforts as well as nature preservation efforts thus have a primarily interpretative rather than manipulative character.

\section{The strongly embodied meaning of nature}

The insight that conservation efforts are driven by an appeal made by nature itself hangs together with the idea that the meaning nature has for us is strongly embodied. One can speak of strongly embodied meanings when the medium through which meaning is conveyed is itself constitutive of the meaning that is conveyed. A good example of a strongly embodied meaning is a poem. ${ }^{24} \mathrm{~A}$ paraphrase of the meaning of a poem can never capture its full meaning. If we were to try and explain what that full meaning is, we can only direct the 
attention back upon the concrete wording of the poem itself, because its meaning is tied up with the specific words of the poem in a specific order. If we change those words, we necessarily change the meaning of the poem. That is of course why it is so hard, if possible at all, to translate poetry without changing, however slightly, it's meaning. It is also why a poem points to a meaning beyond itself precisely by attracting the attention onto itself. The more the concrete wording of a poem becomes unique and unsubstitutable, the more it thus fixes the attention upon itself, the more it points to a meaning beyond itself.

It is my contention that the meaning of nature is similarly strongly embodied. Whatever meaning nature has cannot be grasped but through its concrete, material manifestations. It is precisely the very idea that the meaning of nature is embodied in its concrete manifestations that is denied when conservation is made to serve certain abstract goals, such as the maintenance of biodiversity, or, indeed, some abstract notion of nature's ontological structure. Nature conservation does not concern itself with conserving Nature or Biodiversity, nature conservation is always a response to the appeal from this or that particular piece of nature. Particular natural areas, or indeed species or natural events such as the changing of the seasons or big thunderstorms, sometimes appear as a meaningful unity, a unity that seems to reveal something of the essence of nature. Such units in there concreteness seem to point beyond themselves to some deeper truth or insight. Conservation is a then an attempt to keep the meaning these natural objects presence present. Since that meaning can only be experienced through the concrete materiality of those natural objects, keeping that meaning present entails keeping those objects the way they are.

Such natural objects can be properly called symbols of nature. They are not symbols because they express the meaning nature has for us in the best or most efficient way. Since the meaning of nature can only be fathomed through these particular symbols, we cannot deduce from the meaning nature might have what symbols would be best or most efficient to 
communicate that meaning. We can only grasp the meaning of nature by directing our attention back upon the concrete materiality of these symbols. An example of such a symbol can be found in the work of Aldo Leopold's A Sand County Almanac. ${ }^{25}$ In the chapter Marshland Elegy Leopold describes the crane as "the symbol of our untamable past", which grants a marsh "a paleontological patent of nobility". ${ }^{26}$ If the crane is absent from a marsh, it is as if it gets grief-stricken: "[the] sadness discernable in some marshes arises, perhaps, from their once having harbored cranes". ${ }^{27}$ It is as if the crane is uniquely capable of capturing the meaning of the marsh, granting it nobility. The crane evokes a "world of meaning", the meaning of the marsh, and that meaning is lost if the crane disappears: the marsh forever seems dismembered, its meaning disfigured, even if in all other respects the marsh stays exactly the same. The more the crane in all its particularity becomes unsubstitutable, the stronger it evokes the world of meaning of the marsh: "when we hear its call, we hear no mere bird". ${ }^{28}$ But it is only by listening attentively to the crane's call that we can sense we are hearing more than just a crane signaling its presence.

\section{The Importance and the Danger of Permanence}

Leopold' example of the crane also draws our attention to a further fact. If our desire to conserve nature is a desire to conserve the meaning which reveals itself through strongly embodied symbols, that appeal will be stronger the more we can see, in the words of Arnold Burms, these symbols "as the expression of a certain permanence which transcends the accidentalness of fleeting desires and ambitions. In what strikes us as really important, 'the

past and forever' sounds." ${ }^{, 29}$ The oldest, most permanent will thus appear to have the greatest meaning, seem the weightiest. I believe that the whole Midas complex which plagues environmental philosophy when it comes to "human modification" of nature boils down to a misunderstanding of this fact. If nature appears meaningful it must be able to be seen as the 
expression of a sort of permanence or endurance through time. This permanence is seemingly under threat when nature is made the object of "fleeting desires and ambitions" of humans. Nature, left to its own devices, seems to have a kind of permanence; it seems to transcend the fleeting coincidences of time, if only because the timescales on which it changes far transcend habitual human perception of time, or because its changes appear to be eternally cyclical. If the outlook a particular natural area or the form of a landscape is however seen as the contingent result of certain human practices, nature seemingly becomes the result of the passing, vain and short lived ambitions and projects of humans. The transcendence of nature thus seems jeopardized when nature is seen as the result of the "momentary desires and ambitions" of humans and in an attempt to shield the transcendence of nature preservationists want to purge it from and protect it against all human influence. ${ }^{30}$

What is however crucial to understand is that the appeal that comes from nature does not come from it "not being modified by human hand" itself, but from its permanence through the passage of time. ${ }^{31}$ Here, restoration and preservation find common ground again: they both are directed at ensuring the continuity of the meanings embodied in certain particular natural areas, and those areas have gathered "weight" through their permanence. It is simply not the case that landscapes which have been modified by humans in the past cannot be seen as possessing a certain type of permanence: the pre-industrial European agricultural landscape had a high degree of stability and permanence, even when it changed under new agricultural practices it usually retained features of older forms and practices. It also explains why, even if we have to swallow some initial disappointment, the landscapes of the great North American national parks do not seem to decrease in value now we come to know that some of their most beautiful landscapes are at least partially the result of First Nation burning practices. Such landscapes can still be venerated in their seeming timelessness, and it is this timelessness, this permanence, which speaks to our imagination and strengthens the appeal they make on us. A 
landscape gathers, as it were, meaning over the passage of time through its enduring material presence. ${ }^{32}$

The idea that the meaning we try to conserve through nature conservation practices is embodied in particular material manifestations of nature however also entails that the meaning we seek to preserve is subject to transformations beyond our control. If meaning is tied to a concrete material form, certain changes to that materiality will necessarily affect its meaning. Of course nature is changeable, and not all of the changes nature undergoes are desirable for a conservationist. Such changes might even ultimately destroy all meaning we perceived in a particular natural area. Nature conservation is also about preventing such changes from happening. In this sense, no act of conservation can do without at least a minimum of manipulation.

That there is some manipulation of nature needed is of course clear in restoration efforts. If we do not mow the heath in the Low Countries, it will return to scrubland and eventually forest. Yet such mowing is, as I have tried to show, not directed at recreating nature along the blueprint of some idea of what nature should be like. It is about the interpretation of and the respect for the way in which nature concretely manifests itself in a particular area and about conserving the meaning it conveys. It is about carefully "reading" a particular natural area and seeing how we can enable it to continue its "story", how we can let it continue to "speak" to us. In restoration, nature is thus not made subservient to our ideas or desires any more than it is in preservation. From its side, a preservation effort cannot escape manipulating the natural areas it wants to preserve either. Minimally, strict preservation entails the erecting and patrolling of borders in order to keep human intrusion to a minimum, but usually even the strictest of preserves undergo far greater manipulation. That is why Bernard Williams rightfully claims that: "anything we leave untouched we have already 
touched. It will no doubt be best for us not to forget this, if we are to avoid self-deception and eventual despair." 33

It is however clear that this manipulation cannot go too far: as we have seen, the object of our desire must remain external to our desires. Paradoxically, if we are really interested in conserving nature, we must also be interested in the fact that it will not respond to our conservation efforts, that it will negate our desires. It belongs to the structure of the desire itself that the object of the desire remains recalcitrant to our desires, and thus the possibility of the object not meeting our desires must be a real possibility. Nature conservation efforts will thus always have to operate in a tension between the two poles of manipulating nature to in order to preserve its meaningfulness and giving way to spontaneous processes. Both exerting too much manipulative control over and completely giving in to the unpredictable transformation the materiality of nature is subject to, might eventually destroy the meaning we sought to conserve. We do not however have any direct control over this tension. It is therefore impossible to determine in general how much manipulation and how much surrender to the spontaneous transformation are needed in order for a conservation effort to be successful.

\section{The taboo on reintroductions revisited}

This last point brings us back to Mergeay and De Meester and the irrationality of the taboo on introductions of target species. According to them, the taboo on introductions is irrational because it is inconsistent, allowing for some forms of human manipulation and prohibiting others. We can now however interpret the taboo in another light. Nature conservation is all about enduring the tension between too much and too little manipulative control. But we cannot actively control that tension itself: there is no general goal outside of conservation to which the rightness of certain conservation practices can be measured. Precisely because in 
conservation we must give over to something over which we have no control, because we cannot deduce from any general principal what we must do to strike the right balance in the tension between too much and too little manipulation, the rules around conservation will necessarily have an arbitrary character, in the sense that they will not be able to be deduced from some general goal which conservation should attain, and will always be tied to a specific (cultural) tradition of conservation. In this respect, conservation is like playing a game: the finality of the game cannot be sought outside of the game; its rules are not deduced from a separate finality the attainment of which the game itself is but a substitutable means. The rules themselves constitute the finality of the game, and its meaning can only be understood by playing it, by adhering to its arbitrary rules.

Contrary to what Mergeay and De Meester believe, the taboo on reintroductions is not founded upon an inconsistent deduction from the general principle that nature conservation should be about allowing for spontaneous processes. Indeed, the taboo is arbitrary, and has no rational justification, but it is necessarily so. The alternative, which Mergeay and De Meester propose, is that we do make nature conservation subservient to some general goal, namely biodiversity conservation. But in such a case, we have no reason to bother with nature; it will no longer be clear why we should have any respect for nature at all. If Mergeay and De Meester want to avoid the conclusion that nature conservation is not about respecting nature itself, they will have to, as we have seen, eventually install new rules that will be every bit as arbitrary as the ones they reject on the basis of their arbitrariness.

\section{Conclusion}

We started this paper by remarking that there are differences in sensitivity about the role of humans in conservation between the Old and the New World. Central to both conservation traditions however stood unease about the role of the concept of the "natural" or "wilderness" 
as an evaluative norm for conservation practices. What I have tried to show is how the concept of the "natural" functions in those debates. It is mistake to believe that "the natural" simply refers to things that are "not modified by human hand" or "things that are intrinsically functionless". When one evokes "the natural" as an evaluative concept in conservation efforts, one tacitly refers to the insight that the type of desire we have for nature cannot be satisfied when nature is brought under our total manipulative control, not because of the specific ontological structure of nature, but because of the type of desire we have for it. There is no essential difference between the practices of nature preservation or restoration here: neither nature restoration nor preservation efforts can succeed through instrumentalizing whatever they wish to restore or preserve.

I also tried to show how it is a mistake to claim that conservationists who use "naturalness" as an evaluative norm are inconsistent in their reasoning. If nature conservation is about conserving strongly embodied meanings, than conservation practices cannot be interpreted as being directed at achieving some general goal of which particular natural areas are mere manifestations. Nature conservations is not about manipulating nature in such a way that it better suits the images we have of it: it is a response to an appeal from a particular piece of nature. Conservation therefore should always start with an attentive interpretation of that appeal.

Finally, I tried to show that if nature conservation is about conserving strongly embodied meanings, those meanings that seem the most permanent will have the greatest appeal. When confronted with an age-old landscape, it is thus not because it is the most original or the least humanly influenced that we seem to value it the most, but the fact that it transcends the passage of time, that it has the patent of permanence. Seen from this light, the search for an origin, an origin in which nature appears to be the most pure and thus most 
valuable, is an illusion. Nature gathers value, "weight" or meaning not by being pure or originary, but through endurance. 
Notes

${ }^{1}$ Paul Knights, "Cultural Landscapes, Ecological Restoration and the Intergenerational Narrative," this volume.

${ }^{2}$ In many places, North-American landscapes seem to be as historically layered as European ones, yet this fact had until recently scarcely been recognized, let alone incorporated into conservation practice (See, for instance, Gary Nabhan, "Cultural Parallax in Viewing North American Habitats," in Reinventing Nature: Response to Postmodern Deconstruction, ed. M. Soulé and G. Lease (Washington D.C.: Island Press, 1995), 87-101).

${ }^{3}$ I will use the term "nature conservation" as a general term encompassing both nature "restoration" and "preservation". Sometimes, "nature conservation" is associated with a practice that only recognizes the instrumental value of nature. In such cases, it is contrasted to "nature preservation" which also recognizes the intrinsic value of nature. "Nature conservationists" allow for a managerial approach to nature in order to ensure its maximal sustainable use, while "preservationists" advocate a total hands off approach. "Nature restorations" are then contrasted with "preservation" precisely because in "restorations" humans actively interfere with the course of nature. Whether there is actually a sharp distinction between "restoration" and "preservation" is discussed later in this chapter. For now, it is important to note that I use "conservation" as a general term to encompass both nature preservation and restoration, thereby deviating a little form the common use of the term.

${ }^{4}$ For an excellent history of nature conservation in the context of the Lowlands, see Henny van der Windt, En dan? Wat is natuur nog in dit land? Natuurbescherming in Nederland 1880-1990 (Amsterdam: Boom, 1995). 
${ }^{5}$ I borrowed and translated this term from the work of Piet Schroevers, "Menselijk bemiddelde natuur," in Landschap in meervoud, ed. Jan Kolen and Ton Lemaire, (Utrecht: Jan van Arkel, 1999), 141-160.

${ }^{6}$ Standard paleoecological theory holds that almost all of Europe prior to the advent of agriculture consisted out of closed canopy forests and that if humans were to stop managing nature, a closed canopy forest would reappear. This has always formed a problem for European conservationism, in the sense that many of the species present in our current European landscapes are light-loving species which were able to colonize places beyond their original ranges because of the clearing of the forest for agricultural purposes. Keeping the present species diversity of many European landscapes in place thus depends on keeping spontaneous forest development in check; against the grain of natural succession. There are however ecologists, among which most notably Dutch ecologist Frans Vera, who claim that the original European landscape was more open and park-like due to the (underestimated) effects of grazing by large herbivores on forest development. If one were to reintroduce those large herbivores (or ecological equivalents for those species of herbivores that have gone extinct), natural areas would thus not turn into closed canopy forests, leaving room for many of the light-loving species to survive "under wilderness condition". This would open up the possibility of halting the traditional ways of managing nature without risking the loss of (most of) the light-loving species. (Frans Vera, Metaforen voor wildernis: eik, hazelaar, rund en paard (Wageningen: Landbouwuniversiteit Wageningen, 1997). The theories of Frans Vera have however sparked off a lively ecological debate in which they have been roundly criticized, vindicating the consensus that (at least Western Europe, but probably all of Europe) was and would become a closed canopy forest under wilderness condition. Large herbivores can at best slow down the process of forest succession locally; their overall impact on forest succession under wilderness condition is deemed to be negligible. See Cis van Vuure, De 
Oeros: het spoor terug (Wageningen: Landbouwuniversiteit Wageningen, 2003) and Oliver Rackham, Woodlands (London: Harper Collins, 2006) for an overview of the relevant discussions.

${ }^{7}$ Knights, "Cultural Landscapes,” this volume.

${ }^{8}$ Robert Elliot is of course of Australian origin. However, Australia being part of the New World, Elliot works from an ecological context that is more similar to the American then the European.

${ }^{9}$ Knights, "Cultural Landscapes," this volume. I reinterpreted the work of Elliot to make it suitable for use in a European context in a totally different direction in Glenn Deliège, "The Cinquefoil Controversy. Restoring Relics between Managers and Purists," in Environmental Ethics 32 (2010): 17-32.

${ }^{10}$ Jana Thompson, "Environment as Cultural Heritage," in Environmental Ethics 22 (2000): 247.

${ }^{11}$ Thompson, "Environment as Cultural Heritage," 247.

${ }^{12}$ See foornote 5

${ }^{13}$ Joachim Mergeay and Luc De Meester, "Introducties en rationaliteit in het natuurbeheer," Natuur.Focus 9 (2010): 124-127.

${ }^{14}$ Mergeay and De Meester, "Introducties en rationaliteit in het natuurbeheer," 126.

${ }^{15}$ Kate Rawles remarks that the biodiversity concept indeed seems inherently managerial.

Kate Rawles, "Biological Diversity and Conservation Policy," in Philosophy and Biodiversity, eds Markku Oksanen, Juhani Pietarinen (Cambridge: Cambridge University Press, 2004), 199-216.

${ }^{16}$ Compare Martin Drenthen, "Wildness as a Critical Border Concept: Nietzsche and the Debate on Nature Restoration”, Environmental Values 14 (2005): 317-337

${ }^{17}$ Mergeay and De Meester, "Introducties en rationaliteit in het natuurbeheer," 127. 
${ }^{18}$ Mergeay and De Meester, "Introducties en rationaliteit in het natuurbeheer," 127.

${ }^{19}$ Eric Katz, Nature as Subject. Human Obligation and Natural Community (Lanham:

Rowman \& Littlefield, 1997), 95. Subsequent page numbers in the text refer to this article.

${ }^{20}$ See Robert Elliot, "Faking Nature,” Inquiry 25 (1982): 81-93 and Robert Elliot, Faking

Nature (London: Routledge, 1997). In order to avoid all confusion, Robert Elliot is not necessarily against nature restoration per se, but against what he calls the "restoration thesis", which is the claim that it is unproblematic, in the sense that there would be no loss of value, to destroy a natural area as long as one promises to recreate an exact copy of that natural area afterwards. What is lost in such cases, is according to Elliot precisely the naturalness of an area, yet it is precisely the naturalness of an area that is constitutive of its value. In a sense, Elliot is thus not against nature restoration per se, but shows that a restored natural area will necessarily yield something of less "natural value" than an original natural area.

${ }^{21}$ Katz, Nature as Subject, 114

${ }^{22}$ For the argument developed in this section, I am greatly indebted to the work of Arnold Burms and Herman De Dijn, Rationaliteit en haar grenzen. Kritiek en deconstructie. (Leuven: Universitaire pers Leuven, 1995), especially chapter 1.

${ }^{23}$ Elliot, "Faking Nature," 91.

${ }^{24}$ I take this example from Arnold Burms, "Betekenis, poëzie en onzegbaarheid," in Waarheid, evocatie, symbool (Leuven: Peeters, 2011), 142-146.

${ }^{25}$ Aldo Leopold, A Sand County Almanac (New York: Oxford University Press, 2001), 159160. My attention was drawn to this example through the reading of Simon James, The Presence of Nature (Basingstoke: Palgrave Macmillan, 2009), 83-85. Although my treatment of the symbolic stays very close to his, I stress the importance and consequences of the material embodiment of meanings somewhat more forcefully. 
${ }^{26}$ Aldo Leopold, "Marshland Elegy" in A Sand County Almanac (New York: Oxford University Press, 2001), 160.

${ }^{27}$ Leopold, "Marshland Elegy,” 160.

${ }^{28}$ Leopold, "Marshland Elegy,” 160.

${ }^{29}$ Arnold Burms, "Natuur en symbool," Ethische Perspectieven 18, no. 3 (2008), 328. Translation by author.

${ }^{30}$ Although I cannot develop this point here, I believe that a similar drive lies at the heart of rewilding projects in Europe. It is not because the presumed "wild" landscapes are more originary, or richer, that they are more valuable, but simply because they seem to have more of an air of permanence. Compare: René Munnik, "Natuur en Weerstand," in Het eigen gewicht van de dingen, ed. Koo van der Wal and Maarten Coolen (Budel: Damon, 2003), 4374.

${ }^{31}$ Compare Munnik, "Natuur en Weerstand”. Compare also Alan Holland, Andrew Light and John O’Neill, Environemntal Values, (London\&New York: Routledge, 2008). In many ways, the position for which I am arguing is close to that worked out in Environmental Values; but it would take a new article to sketch the differences between my position and theirs. However, what is clear is that I put a far greater stress on the crucial role material continuity plays in the preservation of meaning than do Holland et.al.

32 This of course also entails that in our present society, when landscapes are arranged and rearranged on a rhythm dictated by a global market fueled by our fleeting desires, the capacity of landscape to gather meaning and appeal through their enduring presence over time, is greatly diminished.

${ }^{33}$ Bernard Williams, "Must a concern for the Environment be Centre don Human Beings?," in Making Sense of Humanity and Other Philosophical Papers (Cambridge: Cambridge University press, 1995), 240. 